\title{
Meeting organizers welcome
}

\author{
Ri-Cheng Chian • Jiayin Liu
}

Published online: 16 February 2013

(C) Springer Science+Business Media New York 2013

It is our honor and privilege to welcome you to the 6th meeting of ISMAAR. Planning for the follow-up to our meeting in May of 2012 in Denmark has involved a concerted effort on the part of our members, the local organizing committee, and the leadership of ISMAAR. We express our deepest gratitude to all who have contributed to making this an outstanding venue and program that is sure to move our goals closer to reality in the coming years. But the work is just beginning if our international congress is to achieve its objective.

ISMAAR is committed to changing the global landscape of human ARTs. Our program this year highlights many of the advances that have taken place in basic and clinical science but without your engagement and participation, the momentum we now appreciate will fall short of our intended purpose. The experts we have convened on this special occasion are just that-international leaders in their respective disciplines who will share their insights and practices with you over the course of several days filled with questions that remain and controversies yet to be resolved. Your role is to take full advantage of these offerings in a forum of open discourse and discussion that will make this meeting one to remember for years to come, and one that will allow ISMAAR to take one step closer to realizing our dreams for our patients and the practice of human ARTs.

So it is, in the spirit of friendship and comraderie that we extend our warmest welcome to our participants, speakers, and honored guests and trust that you take with you memories of our $6^{\text {th }}$ meeting in Nanjing that will endure for years to come.

Capsule ISMAAR is committed to change the global lanscape of human ARTs.

R.-C. Chian · J. Liu

The State Key Laboratory of Reproductive Medicine,

Nanjing Medical University, Nanjing, China

R.-C. Chian $(\bowtie)$

Department of Obstetrics and Gynecology, McGill University,

Montreal, Canada

e-mail: ri-cheng.chian@mcgill.ca 